\title{
Malaria Imported from Ghana by Returning Gold Miners, China, 2013
}

\section{Zhongjie Li, ${ }^{1}$ Yichao Yang, ${ }^{1}$ Ning Xiao, ${ }^{1}$ Sheng Zhou, Kangming Lin, Duoquan Wang, Qian Zhang, Weikang Jiang, Mei Li, Xinyu Feng, Jianxin Yu, Xiang Ren, Shengjie Lai, Junling Sun, Zhongliao Fang, Wenbiao Hu, Archie C.A. Clements, Xiaonong Zhou, Hongjie Yu, Weizhong Yang}

During May-August 2013, a malaria outbreak comprising 874 persons in Shanglin County, China, was detected among 4,052 persons returning from overseas. Ghana was the predominant destination country, and $92.3 \%$ of malarial infections occurred in gold miners. Preventive measures should be enhanced for persons in high-risk occupations traveling to malaria-endemic countries.

$\mathrm{M}$ alaria is a potentially deadly disease caused by infection with Plasmodium spp. parasites, which are transmitted to humans through bites from infected Anopheles spp. mosquitoes. As part of global malaria elimination actions by the World Health Organization, in 2010, the government of China initiated the National Action Plan for Malaria Elimination to eliminate malaria by 2020 (1). In recent years, the incidence of malaria in China has decreased sharply to 0.18 cases per 100,000 persons in 2012 (2). However, imported malaria among persons returning from overseas malaria-endemic regions has been documented in some areas of China $(3,4)$. These imported cases present a new challenge to malaria elimination in China. To facilitate formulation of more effective prevention and control measures for imported malaria at a time of rapidly increasing globalization, we describe the epidemiologic characteristics of a large outbreak of imported malaria among Chinese workers returning from overseas countries, in Shanglin County, Guangxi Zhuang Autonomous Region, in 2013.

Author affiliations: Key Laboratory of Surveillance and Early-warning on Infectious Disease, Chinese Center for Disease Control and Prevention, Beijing, China (Z. Li, S. Zhou, Q. Zhang, J. Yu, X. Ren, S. Lai, J. Sun, H. Yu, W. Yang); Guangxi Zhuang Autonomous Region Center for Diseases Control and Prevention, Nanning, China (Y. Yang, K. Lin, Z. Fang); National Institute of Parasitic Diseases, Chinese Centre for Disease Control and Prevention, Shanghai, China (N. Xiao, D. Wang, W. Jiang, M. Li, X. Feng, X. Zhou); Queensland University of Technology, Brisbane, Queensland, Australia (W. Hu); Australian National University, Canberra, Australian Capital Territory, Australia (A.C.A. Clements)

DOI: http://dx.doi.org/10.3201/eid2105.141712

\section{The Study}

In Shanglin County, since 2006, >10,000 inhabitants have traveled abroad to conduct gold mining work, most of them to Ghana. In late April 2013, the government of Ghana began to strictly regulate the gold mining industry, which forced many gold miners to return to Shanglin County within a short time. In recent years, no locally acquired malaria cases had been reported in Shanglin County; only sporadic cases of imported malaria had been reported. Because Ghana is hyperendemic for malaria, Shanglin County conducted active malaria screening during May 1-August 31, 2013 among 3 groups: 1) persons with an overseas travel history during the previous year, 2) febrile patients visiting hospitals who had no overseas travel history, and 3) asymptomatic local residents who had no overseas travel history but lived in the same household as persons who had malaria.

All persons who had $P$. falciparum infection were treated with artemisinin-based combination therapy; persons who had no glucose-6-phosphate dehydrogenase deficiency and who were infected with $P$. vivax or $P$. ovale were radically cured with chloroquine combined with primaquine; and persons who had $P$. malariae infection were treated with chloroquine. All persons who had malaria were grouped into inpatients and outpatients, and antimalarial treatments differed according to their clinical situations (online Technical Appendix, http://wwwnc.cdc.gov/ EID/article/21/5/14-1712-Techapp1.pdf).

Epidemiologic investigation with a standardized questionnaire was conducted. We also collected data on demographic information, history of overseas travel, dates of illness onset and blood sampling, result of blood testing, clinical features, and treatment.

To evaluate the risk for local transmission of malaria, entomologic investigations using light traps and human landing collections methods were conducted in the 4 villages that had a large number of confirmed malaria cases. The numbers of adult Anopheles mosquitoes were recorded, and the species of adult Anopheles were distinguished.

During the study period, 6,096 persons were tested for Plasmodium spp. infections in Shanglin County: 4,052 persons with histories of overseas travel, 1,316 febrile patients visiting local hospitals, and 728 local residents living with persons who had malaria; no one in the 2 latter groups had traveled overseas (Table 1). We detected 874 persons who had malaria, all of whom had traveled overseas. The attack rate was 216/1,000 persons for the persons returning from overseas. 
Table 1. Results of Plasmodium spp. screening by microscopic examination, Shanglin County, China, May 1-August 31, 2013

\begin{tabular}{lcccc}
\hline Items & Overall & $\begin{array}{c}\text { Persons with } \\
\text { overseas travel }\end{array}$ & $\begin{array}{c}\text { Local febrile patients } \\
\text { with no overseas travel }\end{array}$ & $\begin{array}{c}\text { Local residents with no overseas } \\
\text { travel living with person with malaria }\end{array}$ \\
\hline No. persons screened for malaria & 6,096 & 4,052 & 1,316 & 728 \\
No. detected malaria infection & 874 & 874 & 0 & 0 \\
Attack rate, \% & 14.3 & 21.6 & 0 & 0 \\
\hline No. Plasmodium species & & & 0 & 0 \\
$\quad$ P. falciparum & 827 & 827 & 0 & 0 \\
P. vivax & 42 & 42 & 0 & 0 \\
P. malariae & 1 & 1 & 0 & 0 \\
P. ovale & 1 & 1 & 0 & 0 \\
Plasmodium spp. co-infection ${ }^{*}$ & 3 & 3 & & 0 \\
\hline${ }^{*}$ All were P. falciparum co-infected with P. vivax. & & & 0
\end{tabular}

Of the 874 persons who had malaria, $871(99.7 \%)$ had returned from Ghana, 2 from Myanmar, and 1 from the Republic of the Congo (Brazzaville). These persons resided in 11 towns in Shanglin County; most lived in 3 towns: 310 (35.5\%) in Mingliang, 211 (24.1\%) in Dafeng, and 204 $(23.3 \%)$ in Xiangxian (Figure 1).

Most persons who had malaria were infected with $P$. falciparium (827 [94.6\%]). P. vivax was responsible for 42 (4.8\%) cases; P. malariae and P. ovale accounted for 1 case each. Three persons were co-infected with different Plasmodium spp. (Table 1).

A total of 807 (92.3\%) infected persons were gold miners. Nearly all (864 [98.9\%]) infected persons were males. Mean age was 36.7 years (range 18-64 years), and most (797 [91.2\%]) persons were 20-49 years of age (Figure 2).

A total of 301 (34.4\%) Plasmodium-positive persons had asymptomatic infections. No deaths occurred. The median interval between return date and diagnosis date was 8 days (range 0-28 days; interquartile range 4-18 days). Among the 369 (42.2\%) persons hospitalized for medical treatment, fever $\geq 37.3^{\circ} \mathrm{C}$ (366 [99.2\%]), headache (288
[78.0\%]), and chills (271 [73.4\%]) were the most common symptoms. For hospitalized patients, $P$. falciparium was the predominant species (336 [91.1\%]), and $P$. vivax was responsible for $28(7.6 \%)$ cases. Fourteen $(3.8 \%)$ persons had complicated symptoms. About half $(50.7 \%)$ of the inpatients had mild to moderate anemia, and $21.1 \%$ of those were thrombocytopenic (Table 2).

The median duration of overseas travel was 356 days for persons who had malaria, which did not differ significantly from persons who did not have malaria (median 354 days; $p=0.7709,2$-tailed Wilcoxon test). All persons who had malaria reported no history of malaria before going abroad, and 871 (99.7\%) had taken no mosquito preventive measures during their stay overseas.

A total of 593 Anopheles mosquitoes were collected in the 4 villages that had large numbers of persons who had malaria. All mosquitoes were identified as An. sinensis.

\section{Conclusions}

We report an unusual, large-scale event of imported malaria among gold miners returning from overseas country to
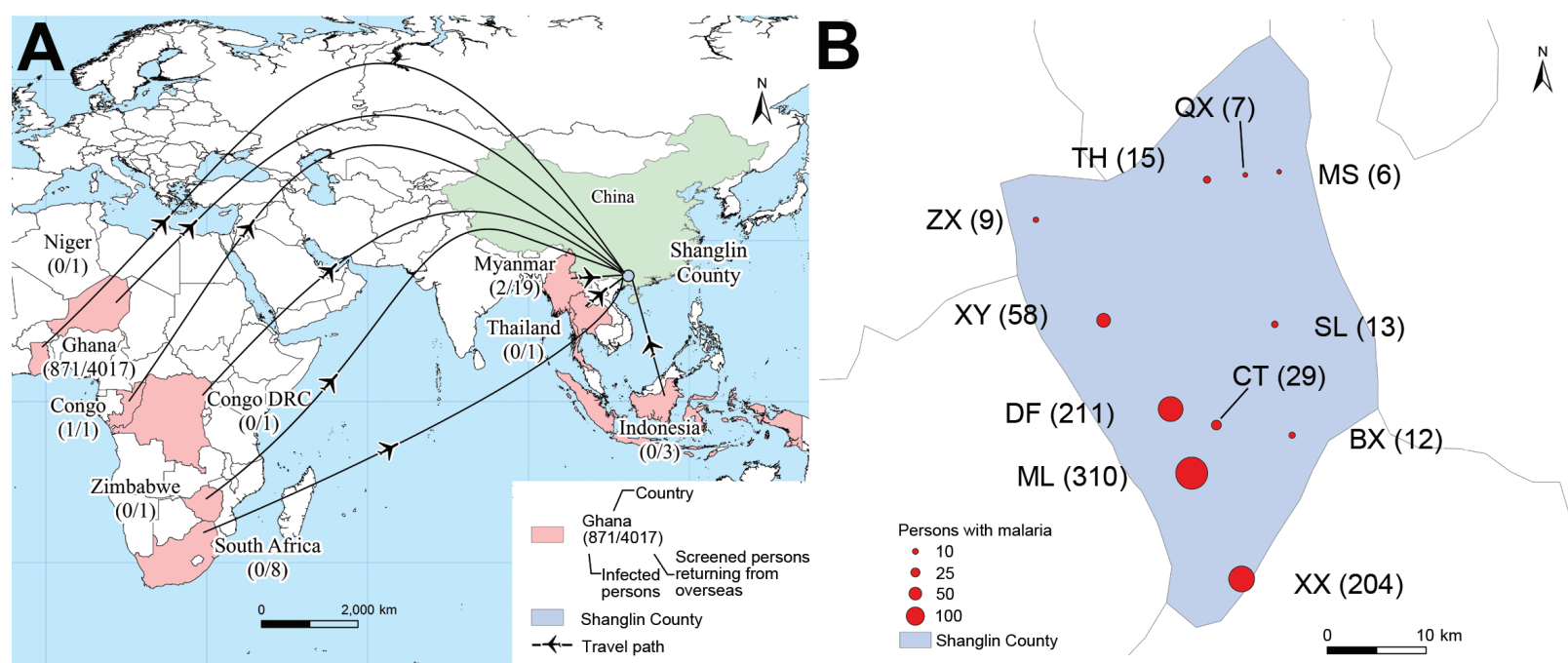

Figure 1. Geographic origin of gold miners returning from oversea (Ghana) and distribution of detected malaria infections, Shanglin County, China, May 1-August 31, 2013. A) Geographic origin of screened miners and persons with malaria. B) Residence of miners who had malaria. DF, Da Feng; ML, Ming Liang; XX, Xiang Xian; CT, Cheng Tai; BX, Bai Xu; SL, San Li; QX, Qiao Xian; MS, Mu Shan; TH, Tang Hong; XY, Xi Yan; ZX-Zhen Xu. 


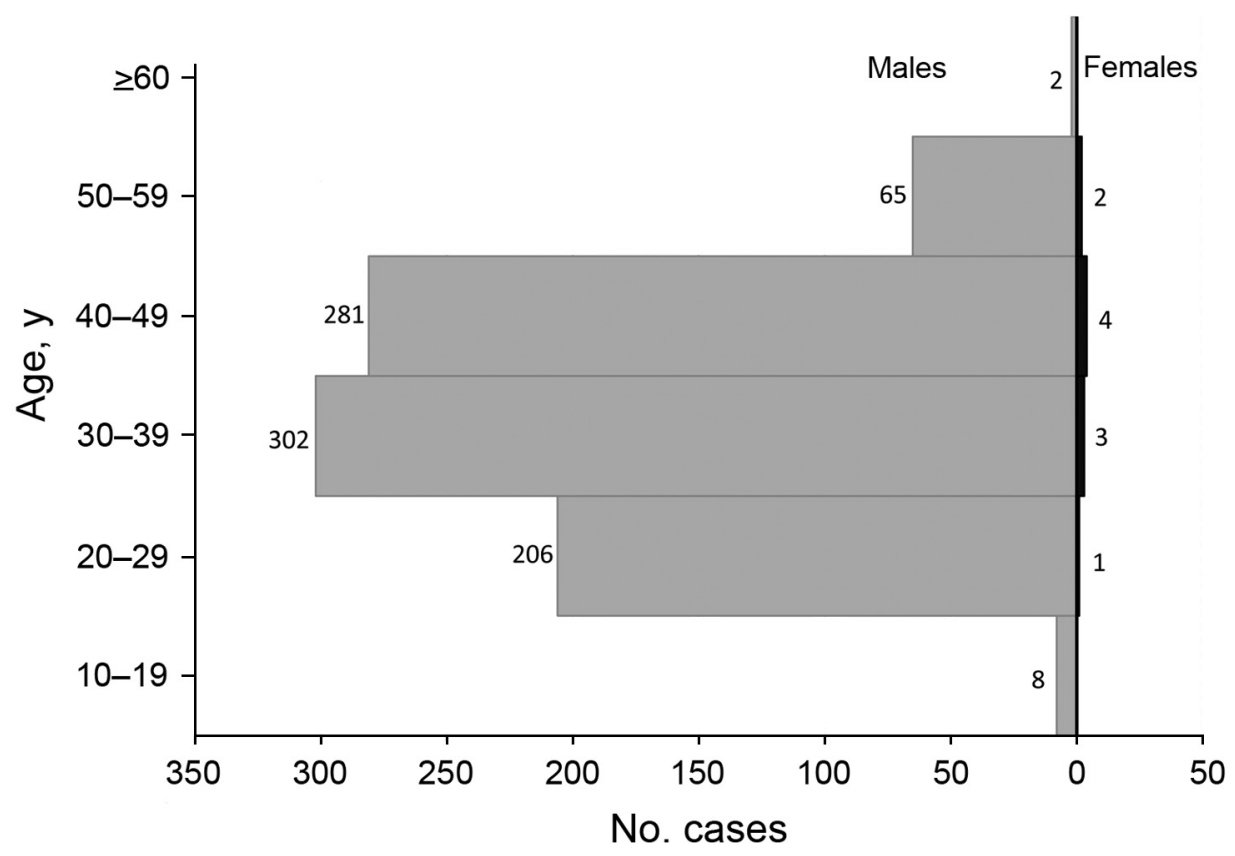

Figure 2. Age and sex of persons who had malaria, Shanglin County, China, May 1-August 31, 2013.

China. Reports have suggested that gold panning activities lead to massive environmental changes, diverting rivers and building basins where vectors can easily breed, thereby increasing the risk for malaria and transmission among gold miners (5-7).

In this outbreak, just over one third (34.4\%) of persons who had malaria were asymptomatic. Because asymptomatic carriers with low-level parasitemia can be reservoirs of infection $(8,9)$, the high proportion of asymptomatic malaria among the returning miners would pose challenges to

\begin{tabular}{lc}
\hline \multicolumn{2}{l}{ Table 2. Clinical manifestation of malaria among hospitalized } \\
persons, Shanglin County, China, May 1 -August $31,2013^{*}$ \\
\hline Variable & No. cases $(\%), \mathrm{n}=369$ \\
\hline Common signs/symptoms & $366(99.2)$ \\
Fever, $\geq 37.3^{\circ} \mathrm{C}$ & $222(60.2)$ \\
Fever $>38^{\circ} \mathrm{C}$ & $288(78.0)$ \\
Headache & $271(73.4)$ \\
Chills & $215(58.3)$ \\
Fatigue & $213(57.7)$ \\
Dizziness/nausea & $65(17.6)$ \\
Sweating & $8(2.2)$ \\
Diarrhea & $14(3.8)$ \\
Complicated symptoms & $7(1.9)$ \\
Liver function impairment & $2(0.5)$ \\
Acute renal dysfunction & $2(0.5)$ \\
Gastrointestinal impairment & $2(0.5)$ \\
Coma & $2(0.5)$ \\
Hemolysis & $1(0.3)$ \\
Cerebral lesion & $1(0.3)$ \\
Severe anemia & $1(0.3)$ \\
Acidosis & $187(50.7)$ \\
\hline Blood test result, reference range & $78(21.1)$ \\
Hemoglobin $<131$ g/L, 130-160 & $45(12.2)$ \\
Platelet count $<85 \times 10^{9} / \mathrm{L}, 85-300$ & \\
G6PD deficiency & \\
${ }^{*}$ G6PD, glucose-6-phosphate dehydrogenase. & \\
&
\end{tabular}

identifying and treating infection, and transmission interruption in China (10).

In this outbreak, no local malaria transmission was identified. A primary reason is that the local predominant anopheline species is $A$. sinensis, which is refractory to $P$. falciparium $(11,12)$.

One of our study limitations was that chemoprophylaxis and detailed exposure history in Ghana were not well documented because most returning miners lacked knowledge and awareness of malaria. In addition, recall was likely to have been poor, given that the miners had lived and worked overseas for a long time at the time of investigation.

Considering the remarkably increasing volumes of cross-border travel, malaria imported from overseas countries is a new challenge for malaria elimination in China, as illustrated by the outbreak reported here. Measures to prevent mosquito bites and chemoprophylaxis should be addressed among groups at high occupational risk for malaria. Clinicians and public health practitioners should enhance their awareness of malaria infection among groups returning from oversea malaria-endemic areas, regardless of whether they have common symptoms. Additionally, entomologic surveillance should be conducted in areas with high risk for imported malaria to assess the risk for local malaria transmission.

\section{Acknowledgments}

We acknowledge Shanglin County Center for Disease Control and Prevention and the clinical institutes in Shanglin County for their assistance in the field investigations and data collection. 
This study was supported by grants from the Ministry of Science and Technology of China (2012ZX10004-201, 2012ZX10004220, 2014BAI13B05) and the Ministry of Health of China (No. 201202006). The funding bodies had no role in study design, data collection and analysis, preparation of the manuscript, or the decision to publish.

Dr. Zhongjie Li is an epidemiologist at the Chinese Center for Disease Control and Prevention. His research interests include the epidemiology of infectious disease and early-warning system on disease outbreak detection.

\section{References}

1. National Health and Family Planning Commission. Action plan of China malaria elimination (2010-2020) [cited 2014 Oct 10]. http://www.nhfpc.gov.cn/jkj/s5873/201005/f84f1c4b0f32420990d23b65a88e2d87.shtml

2. Zhang Q, Lai S, Zheng C, Zhang H, Zhou S, Hu W, et al. The epidemiology of Plasmodium vivax and Plasmodium falciparum malaria in China, 2004-2012: from intensified control to elimination. Malar J. 2014;13:419. http://dx.doi.org/10.1186/ 1475-2875-13-419

3. Liu Y, Hsiang MS, Zhou H, Wang W, Cao Y, Gosling RD, et al. Malaria in overseas labourers returning to China: an analysis of imported malaria in Jiangsu Province, 2001-2011. Malar J. 2014;13:29. http://dx.doi.org/10.1186/1475-2875-13-29

4. Yin JH, Yang MN, Zhou SS, Wang Y, Feng J, Xia ZG. Changing malaria transmission and implications in China towards National Malaria Elimination Programme between 2010 and 2012. PLoS ONE. 2013;8:e74228. http://dx.doi.org/10.1371/ journal.pone. 0074228

5. Coetzee M, van Wyk P, Booman M, Koekemoer LL, Hunt RH. Insecticide resistance in malaria vector mosquitoes in a gold mining town in Ghana and implications for malaria control. Bull Soc Pathol Exot. 2006;99:400-3.
6. Baird JK. Chloroquine resistance in Plasmodium vivax. Antimicrob Agents Chemother. 2004;48:4075-83. http://dx.doi.org/10.1128/ AAC.48.11.4075-4083.2004

7. Berger F, Flamand C, Musset L, Djossou F, Rosine J, Sanquer MA, et al. Investigation of a sudden malaria outbreak in the isolated Amazonian village of Saul, French Guiana, January-April 2009. Am J Trop Med Hyg. 2012;86:591-7. http://dx.doi.org/10.4269/ ajtmh.2012.11-0582

8. Alves FP, Gil LH, Marrelli MT, Ribolla PE, Camargo EP, Da Silva LH. Asymptomatic carriers of Plasmodium spp. as infection source for malaria vector mosquitoes in the Brazilian Amazon. J Med Entomol. 2005;42:777-9. http://dx.doi.org/10.1093/ jmedent $/ 42.5 .777$

9. Okell LC, Bousema T, Griffin JT, Ouedraogo AL, Ghani AC, Drakeley CJ. Factors determining the occurrence of submicroscopic malaria infections and their relevance for control. Nat Commun. 2012;3:1237. http://dx.doi.org/10.1038/ncomms2241

10. Bousema JT, Gouagna LC, Drakeley CJ, Meutstege AM, Okech BA, Akim IN, et al. Plasmodium falciparum gametocyte carriage in asymptomatic children in western Kenya. Malar J. 2004;3:18. http://dx.doi.org/10.1186/1475-2875-3-18

11. Yu G, Yan G, Zhang N, Zhong D, Wang Y, He Z, et al. The Anopheles community and the role of Anopheles minimus on malaria transmission on the China-Myanmar border. Parasit Vectors. 2013;6:264. http://dx.doi.org/10.1186/ 1756-3305-6-264

12. Pan JY, Zhou SS, Zheng X, Huang F, Wang DQ, Shen YZ, et al. Vector capacity of Anopheles sinensis in malaria outbreak areas of central China. Parasit Vectors. 2012;5:136. http://dx.doi. org/10.1186/1756-3305-5-136

Address for correspondence: Weizhong Yang or Hongjie Yu, Chinese Center for Disease Control and Prevention, Key Laboratory of Surveillance and Early-warning on Infectious Disease, 155 Changbai Rd, Changping District, Beijing, 102206, China: email: labsurv@163.com or yuhj@chinacdc.cn

\section{Knemidocoptic Mange in Wild Golden Eagles, California, USA}

Dr. Mike Miller

reads an abridged version of the article, Knemidocoptic Mange in Wild Golden Eagles, California, USA

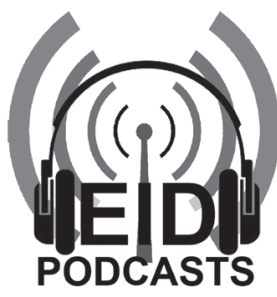

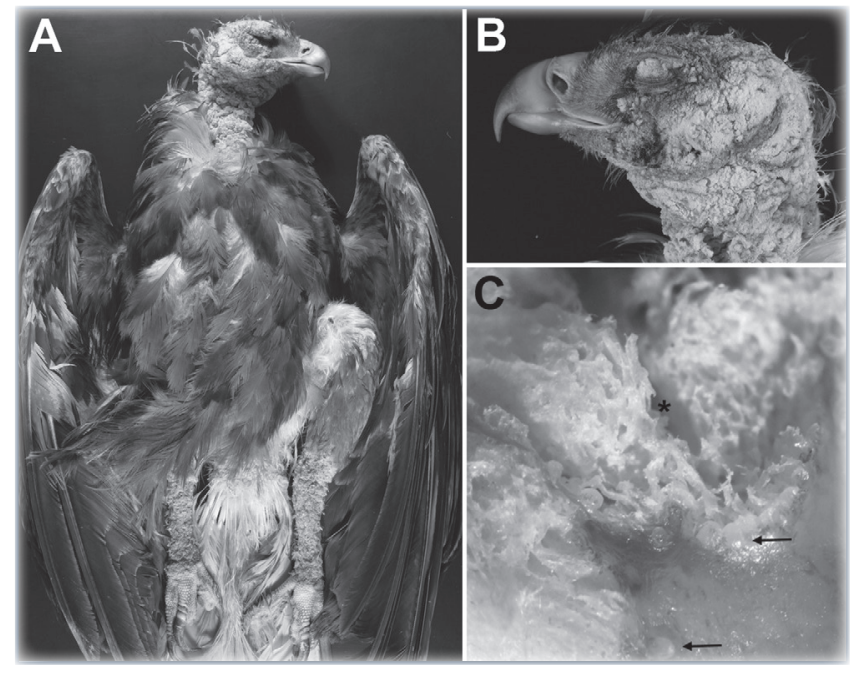

http://www2c.cdc.gov/podcasts/player.asp?f=8634354 